\title{
Aging Mechanisms and Monitoring of Cable Polymers
}

\author{
Nicola Bowler ${ }^{1}$, and Shuaishuai Liu ${ }^{2}$ \\ ${ }^{1,2}$ Iowa State University, Iowa, 50011, USA \\ nbowler@iastate.edu \\ sliu1@iastate.edu
}

\begin{abstract}
Aging mechanisms of two polymeric insulation materials that are used widely in nuclear power plant low-voltage cables; cross-linked polyethylene (XLPE) and ethylene propylene rubber/ethylene propylene diene terpolymer (EPR/EPDM), are reviewed. A summary of various nondestructive methods suitable for evaluation of cable insulation is given. A capacitive sensor capable of making local nondestructive measurements of capacitance and dissipation factor on cable polymers, and potentially suitable for in situ cable monitoring, is introduced. Correlating values of elongation-at-break, indenter modulus, capacitance and dissipation factor measured on a set of 47 aged flame-resistant EPR samples shows a higher correlation between indenter modulus and dissipation factor than between indenter modulus and elongation-at-break.
\end{abstract}

\section{INTRODUCTION}

Approximately $1,000 \mathrm{~km}$ of power, control, instrumentation and other cables are found in a nuclear power plant (NPP). Integrity of NPP cable insulation is crucial for successful reactor shut-down following loss-of-coolant event in containment, and life extension of NPPs beyond their initial operating life requires safe and reliable operation of cables. One important factor in the safety and reliability of cables is the integrity of their polymeric insulation and jacket materials. These materials suffer from degradation due to exposure to heat, radiation and other environmental factors over extended periods of time.

Despite a significant amount of research effort having been devoted to the study of aging cable insulation polymers there is not, presently, a single monitoring method that can be applied to all types of NPP cable for the purpose of obtaining data from which remaining useful life (RUL) of the cable can be predicted. One focus of ongoing research is the identification of new indicators of polymer aging,

Nicola Bowler et al. This is an open-access article distributed under the terms of the Creative Commons Attribution 3.0 United States License, which permits unrestricted use, distribution, and reproduction in any medium, provided the original author and source are credited. which may be measured nondestructively, and used to predict RUL. Validated models that predict RUL of a cable, using nondestructively-measured data as inputs, allow safe and cost-effective life extension of NPPs.

In this paper, various mechanisms of insulation polymers aging are reviewed, particularly in relation to cross-linked polyethylene (XLPE) and ethylene propylene rubber/ ethylene propylene diene terpolymer (EPR/EPDM), Section 3. Various methods that may be applied for nondestructive evaluation of wire and cable polymers are then summarized, Section 4. Also in Section 4, a capacitive sensing method that measures the dielectric properties of wire insulation is introduced. It is shown that measurements of dissipation factor made on aged samples of flame-resistant EPR correlate very well with measured values of indenter modulus, a nondestructive mechanical test method, made on the same samples. This result is an encouraging step towards practical implementation of an original sensor for monitoring cable aging.

\section{BACKGROUND}

A basic cable comprises a central conductor, formed from copper or aluminum strands that are often tin-coated, covered by a polymeric electrical insulation layer, protected by a plastic jacket. Commonly, shielding layers are also applied between these three components. Examples of cables with this construction are low- and medium-voltage power cables. Multi-conductor cables comprise multiple insulated cables housed within a single jacket. Control, instrumentation and data cables are examples of these. Specialized cables, such as nuclear-rated, high-temperature and fire-rated cables, are used in particular environments.

Over extended periods of service, the cable insulation and plastic jacket suffer from degradation due to environmental influences such as heat, ionizing radiation, immersion in water, etc, and may eventually fail due to the formation and propagation of microcracks through the material leading to large cracks. The cable is then no longer properly insulated and current-arcing may lead to loss of power or control function (White II, Bernstein, \& Gillen, 2012). Degradation 
of the cable jacket and electrical insulation layer has, therefore, been identified as a factor that potentially limits the ability of cables to operate beyond their initial design life.

In the 1994 Electric Power Research Institute [EPRI] report, qualified in-containment low-voltage cable products used in the United States nuclear power industry were surveyed. Considering 106 U. S. nuclear power plants and 34 manufacturers, it was determined that cross-linked polyethylene (XLPE) and ethylene propylene rubber/ ethylene propylene diene terpolymer (EPR/EPDM) are prevalent insulation materials, being found within containment in $89 \%$ and $73 \%$, respectively, of the NPPs surveyed. Prevalence was found to fall sharply, to less than $30 \%$, for silicone rubber (SR) and chlorosulfonated polyethylene (CSPE), to below $20 \%$ for ethylene tetrafluoroethylene (ETFE) and to less than $10 \%$ for others including polyvinylchloride (PVC), polyethylene (PE), neoprene, polyalkane and ethylene chloro-trifluoroethylene (ECTFE). These results presented in the EPRI report (1994) are summarized in Figure 1.

In a report emerging from the Light Water Reactor Sustainability Program Nondestructive Evaluation (NDE) roadmapping workshop held in Knoxville, TN in July 2012 (Simmons, Ramuhalli, Brenchley, Coble, Hashemian, Konnick, \& Ray, 2012), it is stated that three key areas of importance are

'determining key indicators of cable aging that correlate with measureable changes in material properties at macroscopic scale,'

ii) 'advance state-of-the-art in current cable NDE methods and develop new and transformational NDE methods,' and

iii) 'develop models for predicting remaining useful life of cables based on condition indices.'

The focus of this article is related to the first two of these areas of importance. In Section 3, mechanisms of polymer aging are discussed. Knowledge of the way in which a material fundamentally changes over time, in response to its environment, underlies development of successful monitoring techniques and of predictive aging models. In Section 4, well-established methods for cable monitoring are surveyed, the principles of capacitive sensing are introduced and an experiment is described in which the performance of a novel capacitive sensor is compared with that of other methods. A conclusion and suggestions for future work are provided in Section 5.

\section{Mechanisms of Insulation Polymers Aging}

In this section, the aging behavior and mechanisms of XLPE and EPR/EPDM are discussed, being the most prevalent of the low-voltage cable insulation materials utilized within reactor containment, Figure 1. Selected physical and electrical properties of XLPE and EPR are summarized in Table 1 .

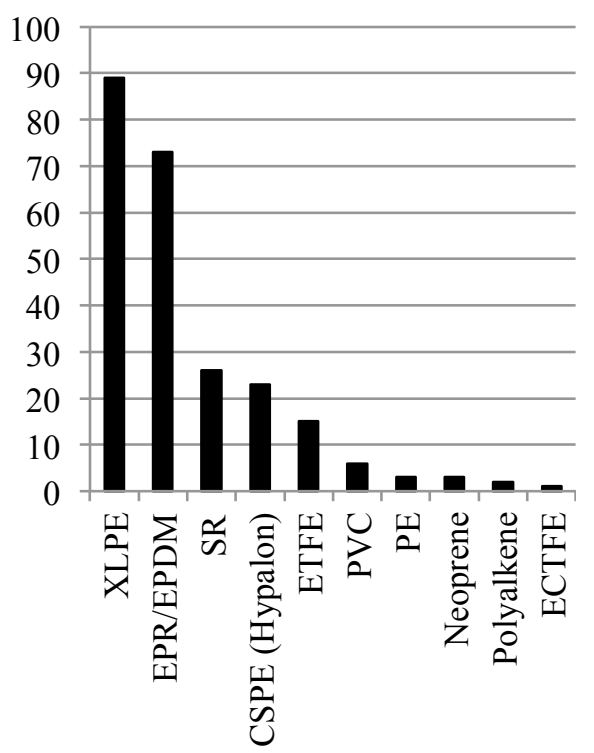

Figure 1. Percentages of United States NPPs with the incontainment cable insulation polymers shown (EPRI, 1994).

Table 1. Selected physical and electrical properties of XLPE and EPR thermosets with temperature rating $105^{\circ} \mathrm{C}$. The dielectric constant and loss tangent were measured at frequency $50 \mathrm{~Hz}$. The data is taken from references (Meyer, Bouquet, \& Alger, 1956; Chapiro, 1962; Ugbolue, 2009;

White, Wagenblast, \& Shaw, 2000; Pires, Mauler, \& Liberman, 2004; Sekii, 2007; Sandia National Laboratories Report, 2010; Seguchi, Tamura, Ohshima, Shimada, \& Kudoh, 2011; Fothergill, Dodd, Dissado, Liu, \& Nilsson, 2011; Wright \& Lesser 2001).

\begin{tabular}{|c|c|c|}
\hline Property & XLPE & EPR \\
\hline $\begin{array}{l}\text { Ethylene content } \\
\text { (wt. \%) }\end{array}$ & $\sim 100$ & 45 to 80 \\
\hline Density $\left(\mathrm{g} / \mathrm{cm}^{3}\right)$ & 0.90 to 0.93 & 0.855 to 0.880 \\
\hline $\begin{array}{l}\text { Tensile strength } \\
\left(\mathrm{N} / \mathrm{mm}^{2}\right)\end{array}$ & $\sim 20$ & 7 to 21 \\
\hline $\begin{array}{l}\text { Elongation at break } \\
(\%)\end{array}$ & 350 to 450 & 100 to 600 \\
\hline $\begin{array}{l}\text { Glass transition } \\
\text { temperature }\left({ }^{\circ} \mathrm{C}\right)\end{array}$ & -130 to -80 & -60 \\
\hline Crystallinity (\%) & $30-55$ & $\begin{array}{l}0 \text { to } 50 \text { (often } \\
\text { amorphous) }\end{array}$ \\
\hline $\begin{array}{l}\text { Melting temperature } \\
\left({ }^{\circ} \mathrm{C}\right)\end{array}$ & 110 to 125 & 120 to 130 \\
\hline $\begin{array}{l}\text { Volume resistivity at } \\
\text { room temp. }(\Omega \mathrm{cm})\end{array}$ & $>10^{16}$ & $\sim 5 \times 10^{16}$ \\
\hline Dielectric constant & $\sim 2.5$ & $\sim 2.0$ \\
\hline $\begin{array}{l}\text { Dielectric loss } \\
\text { tangent }\end{array}$ & $<10^{-5}$ & $\sim 0.0015$ \\
\hline $\begin{array}{l}\text { Dielectric strength } \\
(\mathrm{kV} / \mathrm{mm})\end{array}$ & $\begin{array}{l}\sim 20 \text { (thickness } \\
\text { not specified) }\end{array}$ & $\begin{array}{l}\sim 40 \text { (1-mm } \\
\text { sample thickness) }\end{array}$ \\
\hline
\end{tabular}




\subsection{Arrhenius and Non-Arrhenius Behaviors}

In the study of cable insulation degradation in the laboratory, it is normal practice to age samples at elevated temperature. A very common approach to predict cable insulation aging is the Arrhenius methodology (Wise, Gillen, \& Clough, 1995), which requires that the temperature-dependent change in the dominant degradation mechanism is negligible. However, current research has suggested that, in most cases, the Arrhenius description of polymer aging over a wide temperature range is not valid. Considerable evidence has shown that, in some cases, polymer lifetimes in lower temperatures are overestimated by extrapolations from high temperature aging because of the complex nature of polymer degradation (Tamblyn \& Newland, 1965; Howard, 1973; Kramer \& Koppelmann, 1986; Gillen, Celina, Clough, \& Wise, 1997; International Atomic Energy Agency, 2012). The differences between degradation by accelerated aging and actual aging have been investigated by many researchers and a great number of results have been reported (International Electrotechnical Commission, 1996; International Atomic Energy Agency, 2000; Japan Nuclear Energy Safety Organization, 2009). Research has indicated that the polymer degradation has to do with many factors, including morphological features and their related transition temperature (Billingham, Bott, \& Danke, 1981) diffusion-limited oxidation effects occurring at elevated temperatures (Gillen, Clough, \& Quintana, 1987; Clough \& Gillen, 1992; Wise et al., 1995; Dole \& Cauchard, 1995; Wise, Gillen, \& Clough, 1997), solubility and volatility of stabilizers (Bair, 1973; Howard \& Gilroy, 1975; Board \& Ruddell, 1982), and some other kinetic heterogeneities (Celina \& George, 1993; Celina \& George, 1995). XLPE is a typical cable insulation that shows nonArrhenius behavior (IAEA, 2012), and the major reason is, according to existing research (Gillen \& Clough, 1985; Gillen \& Clough, 1989; Celina, Gillen, \& Clough, 1998; SAND, 2010; Seguchi et al., 2011; Verardi, Fabiani, \& Montanari; 2014), that the degradation mechanism at temperatures above the melting point of XLPE is fundamentally different from the degradation mechanism at temperatures below its melting temperature. The melting point lies between 110 and $125{ }^{\circ} \mathrm{C}$, corresponding to crystalline weight fraction between 50 and $100 \%$. In other words, the temperature and the physical state of the polymer cannot be considered as two independent parameters. When the temperature rises and approaches the crystalline melting point, the crystallites gradually disappear and hence the degree of crystallinity of the polymer changes. Furthermore, the change in degree of crystallinity, i.e. the disappearance of crystallite, gives rise to further changes such as the reaction between free radicals and oxygen. For semicrystalline polymers (XLPE and most EPR), free radicals in the amorphous regions have ready access to a number of chemical processes such as reaction with oxygen, inducing polymer degradation. Within the crystalline regions, on the other hand, there exist free radicals that are firmly trapped there at low temperatures. When the temperature is increased, however, such radicals are released as the crystallites melt, becoming involved in a number of chemical reactions. Above and below the melting temperature, therefore, there are fundamental differences in the degradation mechanisms of XLPE and EPR/EPDM. For these reasons, when studying the lifetime of semi-crystalline cable insulation materials by aging at elevated temperature, the best practice is to choose aging temperatures below the melting point in order to obtain reliable lifetime prediction (Placek 2005; IAEA 2012).

\subsection{Gas Evolution}

Gases are usually evolved in polymer radiation-induced degradation processes. The composition of the evolved gases and their yields are closely related to whether oxygen is present or not, and to the molecular structure of polymer. The gases produced by radiolysis have been widely studied for various polymer materials (Chapiro, 1962; Hegazy, Sasuga, Nishii, \& Seguchi, 1992; Perera \& Hill, 1999). For both XLPE and EPR, aged when oxygen is absent, the gases yielded are mainly $\mathrm{H}_{2}$ and low-molecular-weight hydrocarbons such as $\mathrm{CH}_{4}$ and $\mathrm{C}_{3} \mathrm{H}_{8}$ (Seguchi, Haruyama, \& Sugimoto, 2013). The yield of gas is usually much higher if the irradiation is carried out at higher temperatures and particularly if the polymer is irradiated above its glass transition temperature (Clough, Gillen, Campan, Gaussens, Schonbacher, Wilski, \& Machi, 1984). When oxygen is present during the aging process, however, $\mathrm{H}_{2} \mathrm{O}$ is the major evolved gas, followed by $\mathrm{CO}_{2}$ (Hegazy et al., 1992). When bulky pieces of plastic are irradiated, some of the evolved gas is trapped in the polymer, producing internal pressure and resulting strain. This effect may contribute significantly to the loss of both mechanical and electrical performance. In some cases, the internal strain is sufficient to develop cracks in a plastic sample.

\subsection{Cross-Linking and/or Chain Scission under Irradiation}

When polymers are going through the degradation process, molecular changes take place, such as chain scission, chain cross-linking, depolymerization, and oxidation. Chain scission and chain cross-linking are essentially opposite processes but both may occur simultaneously in the same polymer. Whether a polymer undergoes cross-linking or chain scission under irradiation depends on which process dominates i.e. if cross-linking occurs at a higher yield than chain scission, the net result is cross-linking under irradiation; whereas if chain scission is dominant, the polymer degrades. Both processes depend largely on the presence of oxygen (Joichi \& Yoshitomo, 2003; Clough, Gillen, \& Quintana, 1985; Wilski, Rosinger, \& Diedrich, 
1980; Wundrich, 1968), and both are also temperature dependent. Joichi \& Yoshitomo (2003) studied the mechanical properties of polyethylene (PE) in both vacuum and air. When the PE samples were irradiated in vacuum, the tensile strength first increased by more than $100 \%$ in response to a dose of around 1.2 MGy, after which it started to decrease. When the PE samples were irradiated in air, however, the tensile strength decreased monotonically as radiation dose increased. In other words, polymers that predominantly cross-link when irradiated under vacuum or inert atmosphere may undergo chain scission-dominated degradation when irradiated in the presence of oxygen (Clough et al., 1985). Such differences due to the presence of oxygen can translate into large macroscopic property changes (Wundrich, 1968; Wilski et al., 1980). For example, so-called 'inverse temperature' effects have been reported by a number of researchers (SAND, 2010; Gillen, Assink, \& Bernstein, 2005). This term describes an observed phenomenon in which the degradation can be more rapid at lower temperatures. One explanation for the inverse temperature effect is that at high temperatures the chemical species produced by irradiation-induced chain scission can more easily react among themselves (cross-link), thereby reducing the content of free radicals in the polymer matrix and consequently reducing the extent of aging (Verardi et al., 2014). Studies have also shown that the gel fraction decreases in the region of oxidation and increases elsewhere (Chapiro, 1962; Shimada, Sugimoto, Kudoh, Tamura, \& Seguchi, 2012). These facts indicate that the threedimensional cross-linking of XLPE is reduced by chain scission in the presence of oxygen but the fraction of crosslinking increases when oxygen is absent.

\subsection{Antioxidant and Antioxidant Effect for Polymers}

The activation energy of thermo-oxidative degradation changes over the range from 100 to $120{ }^{\circ} \mathrm{C}$ for both XLPE and EPR (Seguchi et al., 2011). One reason is that, as mentioned above, the crystallinity and the crystallite size changes over this temperature range, leading to the release of free radicals when the temperature is in the vicinity of the polymer's melting point. Additionally, the content of antioxidant decreases with aging time during accelerated aging, caused by evaporation in the case of thermal aging and by decomposition for radiation aging. Usually an abrupt decline in the mechanical properties takes place when the content of antioxidant decreases below a critical value (Seguchi et al., 2011; Kurihara, Takahashi, Honma, \& Okamto, 2011; Seguchi, Tamura, Shimada, Sugimoto, \& Kudoh, 2012).

Antioxidants are organic compounds and are of many species, which may be grouped together as phenol, amine, sulfur, and phosphine (Haruna, 2003). The antioxidant content in cable polymers formulation constitutes about 0.5 to $1.0 \mathrm{phr}$ (parts per hundred resin) for crystalline polymers, and 1.0 to $2.0 \mathrm{phr}$ for rubbery polymers (Seguchi et al., 2012). One mechanism by which antioxidants retard the degradation process has been suggested, by Conley (1970) and Osawa (1992), to be by chain reaction with peroxy radicals and hydro-peroxide. In this scenario, the role of the antioxidant is the termination of free radicals or the decomposition of hydro-peroxides in oxidized polymer chains. Recently, however, other researchers (Seguchi et al., 2011; Seguchi et al., 2012; Sugimoto, Shimada, Kudoh, Tamura, \& Seguchi, 2013) studied sets of XLPE specimens containing different contents of a specific antioxidant. They observed that the antioxidant was very effective as a stabilizer against thermal oxidation, but was not effective against radiation-induced oxidation. In contrast with the mechanism proposed earlier (Conley, 1970; Osawa, 1992), Seguchi et al. (2011; 2012) and Sugimoto et al. (2013) proposed that, rather than the termination of free radicals such as peroxy radicals in polymer chains, the effect of antioxidant is the depression of initial radical formation in polymer chains by thermal activation.

\subsection{Inhomogeneous Oxidation}

Cable insulation polymers are subjected in most practical cases to irradiation at dose rates of approximately $10^{-2}$ to 1 $\mathrm{Gy} / \mathrm{h}$ at between 60 and $90{ }^{\circ} \mathrm{C}$ for a long period of time, usually 40 years and more (Sandia National Laboratories Report, 1986). Laboratory studies of radiation aging of polymers are usually conducted at elevated dose rates, however. Dose rate has a great influence on the extent of radiation-induced oxidative degradation due to both physical and chemical effects.

One important physical effect of radiation dose rate is diffusion-limited oxidation, which takes place when degradation reactions occur faster than oxygen diffusion processes from the ambient air, such that the oxygen dissolved in the polymer cannot be readily replenished (Seguchi, Hashimoto, Arakawa, Hayakawa, Kawakami, \& Kuriyama, 1981; Clough et al., 1985; Shimada, Sugimoto, Kudoh, Tamura, \& Seguchi, 2012). In these circumstances, the concentration of oxygen in the polymer interior is reduced from its equilibrium value to lower or even nonexistent levels. Apart from reducing the dose rate, two other approaches can be taken to help solve the problem of diffusion-limited oxidation due to high dose rate in accelerated aging experiments: thinner samples and/or higher oxygen pressures may be used.

In their study of polyvinylchloride and polyethylene, Clough \& Gillen (1981) found that the thermal decomposition of hydroperoxides, a radiation oxidation product, can lead to an important chemical dose-rate effect. Hydroperoxide breakdown gives free radicals $(\mathrm{R} \bullet)$ via chain branching, as shown schematically below: 


$$
\begin{aligned}
& \mathrm{RO}_{2} \mathrm{H} \rightarrow \mathrm{RO} \bullet+\bullet \mathrm{OH} \\
& \mathrm{RO} \bullet+\mathrm{RH} \rightarrow \mathrm{ROH}+\mathrm{R} \bullet \\
& \quad \cdot \mathrm{OH}+\mathrm{RH} \rightarrow \mathrm{H}_{2} \mathrm{O}+\mathrm{R} \bullet
\end{aligned}
$$

The free radicals $(\mathrm{R} \bullet)$ produced then reinitiate the sequence of scission and/or cross-linking, as described in Section 3.3. Under long-term irradiation at low dose-rate conditions, this step is thought to contribute substantially or even dominate the direct action of the radiation as a source of free radicals (Clough \& Gillen, 1981; Gillen \& Clough, 1985). Under conditions of short-term, high-dose rate exposure, however, this hydroperoxide-mediated chain branching step may not emerge, even at the same total dose as in a long-term low dose-rate experiment. Physical effects of polymer aging that depend on radiation dose rate can be eliminated by the approaches mentioned above, but the chemical dose rate effect is hard to eliminate. For this reason, the best practice is to use as low dose rate as possible to achieve the desired total dose, in an accelerated aging experiment.

\section{Monitoring Cable Polymers Aging}

\subsection{Review of Cable Polymers Testing Methods}

Present acceptance criteria for cable insulation in NPP relate to destructive, mechanical, elongation-at-break (EAB) measurements, requiring $\mathrm{EAB}>50 \%$ for acceptance (EPRI, 2005). EAB is typically measured on cable jacket materials by die-cutting a dog-bone shaped sample and then conducting a tensile test according to, for example, ASTM D412-06a (2013). EAB of cable insulation is normally measured by removing the inner conductor to obtain a tubular specimen whose ends are grasped by a tensile tester as described in a report of the Japanese Standards Association (2000). Through extensive correlation studies, the EAB acceptance criterion has been related to nondestructive measurements of indenter modulus (IM), which is measured by making a controlled mechanical indentation into the cable jacket or insulation and can be performed in situ in some cases (Analysis and Measurement Services Corporation, 2014). The IM measurement suffers from the serious deficiency that it has not been possible to obtain satisfactory correlations between IM and EAB in the case of semi-crystalline polymers (EPRI, 2005), which account for approximately half of the in-containment insulated cable (EPRI, 1994).

The need for monitoring of wire and cable insulation evaluation is not exclusive to the nuclear power industry. Indeed, extensive work has been done related to ensuring the integrity of wiring insulation in air- and spacecraft, and in high-voltage power applications. Some of this activity is directed towards the detection of 'hard' faults such as breaks in the wire conductor. For these faults various types of reflectometry have been investigated (Furse, Chung, Dangol, Nielsen, Mabey, \& Woodward, 2003; Smith, Furse, \& Gunther, 2005; Furse, Chung, Lo, \& Pendayala, 2006;
Chung, Amarnath, \& Furse, 2009). Of greater relevance here is work which pays attention to so-called 'soft' faults in the insulation material itself.

The most widely applied method for aircraft wiring inspection is visual inspection, which is labor-intensive and gives no quantitative information on the insulation condition. More technical methods aimed at assessing the condition of wiring insulation include X-ray, ultrasonic, thermographic, terahertz and electrical approaches. Portable pulsed X-ray systems can be used to obtain radiographic images of a portion of the wire or cable and infrared thermography can be used to examine large regions of wiring insulation rapidly (White, Tucholski, \& Green, 2003). By modeling insulated wire as a cylindrical waveguide, ultrasonic methods have been developed for quantitative assessment of degradation in wiring insulation (Anastasi \& Madaras, 2005). A terahertz study of photodegraded polyethylene has been presented by Hosobuchi, Komatsu, Xie, Cheng, Furukawa, Ohki, Mizuno, \& Fukunaga (2013). Partial electrical discharge (PD) analysis methods for diagnosing aircraft wiring faults are investigated in Desai, Brown, Desmulliez, \& Sutherland (2008), exploiting a simulation of the PD signal based on a high-voltage insulation testing standard (British standard guide, 2001).

\subsection{Principles of Capacitive Testing}

The methods mentioned above generally require complex instrumentation and some are deficient in providing quantitative information about the insulation condition at specific locations. One potential solution of this inspection problem is localized capacitive sensing, whose measurements can be made using relatively simple equipment such as a typical inductance-capacitanceresistance (LCR) meter connected to a suitable capacitive probe. Capacitance (C) and dissipation factor (D) measured by a capacitive probe clamped to an insulated wire or cable jacket are influenced by the electrical property (complex permittivity, $\varepsilon^{*}=\varepsilon^{\prime}-j \varepsilon^{\prime \prime}$ ) of the polymer, which is, in turn, a function of its condition.

A typical LCR meter measures $\mathrm{C}$ as the real part and D as the loss factor of a complex capacitance, $C^{*}$, where

$$
\mathrm{C}^{*}=\mathrm{C}(1-j \mathrm{D}) \text {. }
$$

The capacitance of the well-known parallel-plate capacitor is related to the area of one of its two identical electrodes, $A$, the complex permittivity of the dielectric medium separating the electrodes, $\varepsilon^{*}$, and its uniform thickness, $d$, by the relation

$$
\mathrm{C}^{*}=\varepsilon^{*} A / d
$$

For the parallel-plate geometry, therefore, measured $\mathrm{C}$ and $\mathrm{D}$ are related to dielectric material properties $\boldsymbol{\varepsilon}^{\prime}$ and $\boldsymbol{\varepsilon}^{\prime \prime}$ through the relations $\mathrm{C}=\varepsilon^{\prime} A / d$ and $\mathrm{D}=\varepsilon^{\prime \prime} / \varepsilon^{\prime}$. 
a)

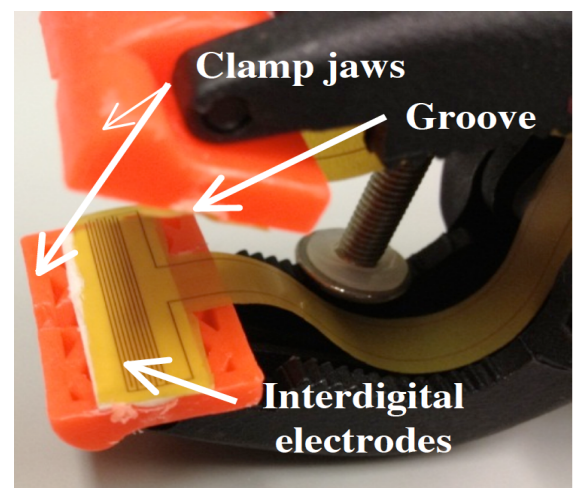

b)

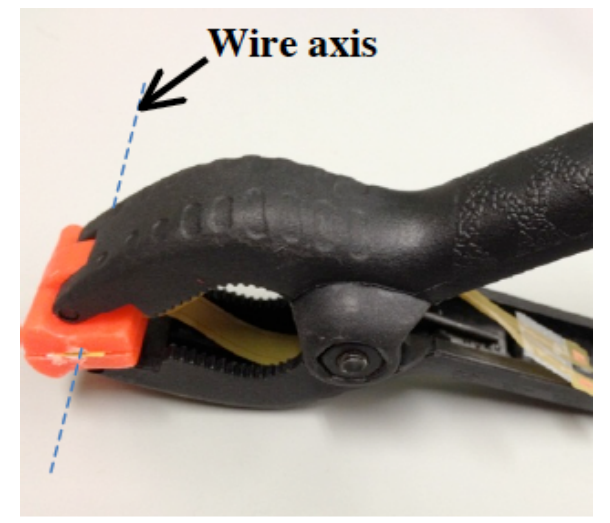

Figure 2. Interdigital sensor is affixed to both faces of the hinged orange jaws of the clamp shown. A groove and foam substrate, holds the wire securely (a). Spring-loading of the clamp ensures good contact with wire under test (b). The electrodes area shown is approximately $25 \times 5 \mathrm{~mm}^{2}$.

For electrodes and test materials with more complex geometry, the capacitance can be calculated based on computational determination of the charge density on the electrodes and employment of the definition of capacitance, that $\mathrm{C}^{*}$ is given by the total charge on one electrode per unit potential difference between the electrodes. Methods for calculating capacitance are available in the literature for various electrode configurations (Chen, Bowler, \& Bowler, 2012; Chen \& Bowler, 2012a; Chen \& Bowler, 2012b, Sheldon \& Bowler, 2014).

\subsection{Permittivity of Polymers}

The permittivity of a typical polymer measured at any particular frequency is the sum of several contributions. At lower frequencies, below around $1 \mathrm{~Hz}$ for example, there may be contributions from interfacial polarization, dipolar polarization and electronic polarization. Interfacial polarization arises in semi-crystalline polymers when migratory charges such as ionic impurities become trapped at the boundaries between the crystalline and amorphous regions in the polymer. In this case an electric dipole is induced on the length-scale of the semi-crystalline region, when an electric field is applied to the polymer. Interfacial polarization may also occur in polymers loaded with nano- or micro-particles. Other contributions to permittivity in a polymer arise from the presence of permanent electric dipoles due to charge displacement in particular molecular groups. Permanent dipoles may be associated with charge separation that occurs across sub-groups of the polymer backbone and/or molecular side-groups. The extent to which any particular dipole contributes to the total permittivity of the polymer is related to its ability to rotate and align itself with the direction of an applied electric field. Dipoles associated with the polymer backbone typically contribute to the polymer permittivity only at temperatures higher than the glass transition temperature, when they become mobile. For many polymers, therefore, the permittivity varies as a function of frequency, depending on which of the above mechanisms are participating in the polarization of the material. Figure 3 illustrates the frequency-dependence of polymer permittivity schematically. The $\alpha$-relaxation is associated with motions of the polymer backbone whereas the $\beta$ relaxation is associated with the motion of molecular side-groups. Higher-frequency relaxation of other side-groups are named $\gamma, \delta$, etc. Electronic polarization arises due to relative displacement of electronic and nuclear charge under the influence of the applied electric field and persists up to around $10^{15} \mathrm{~Hz}$.

The polarization mechanisms illustrated in Figure 3 each pass through a relaxation at their own characteristic frequency. The relaxation frequency is determined by the environment of each dipole and its ability to rotate in response to the cycling of the applied electric field. At frequencies below the relaxation frequency, the dipole contributes to the overall polarization of the polymer because its orientation changes in response to the switching of the electric field. At frequencies well above the relaxation frequency, however, the dipole is not capable of responding to the changing direction of the rapidly cycling applied electric field and no longer contributes to the polymer polarization. The real permittivity of a typical polymer therefore declines as frequency increases, as shown in Figure 3. Associated with the decline in the real permittivity that characterizes a dielectric relaxation, a peak in the imaginary permittivity is observed. This behavior is predicted by the Kramers-Kronig relations and originates in the principle of causality (Jonscher, 1983).

\subsection{Dielectric and Mechanical Measurements on Aged Wire Insulation}

Recently, an interdigital capacitive sensor that can be employed to evaluate the condition of wire insulation has been designed (Sheldon \& Bowler, 2014), Figure 2. The sensor has been tested on aged wires insulated with flameresistant (FR-) EPR of three colors; black, white and red. The FR-EPR samples were aged at 80,90 or $100{ }^{\circ} \mathrm{C}$ and radiation level $100 \mathrm{~Gy} / \mathrm{h}$ for exposure times between 1,177 and 5,781 h. 


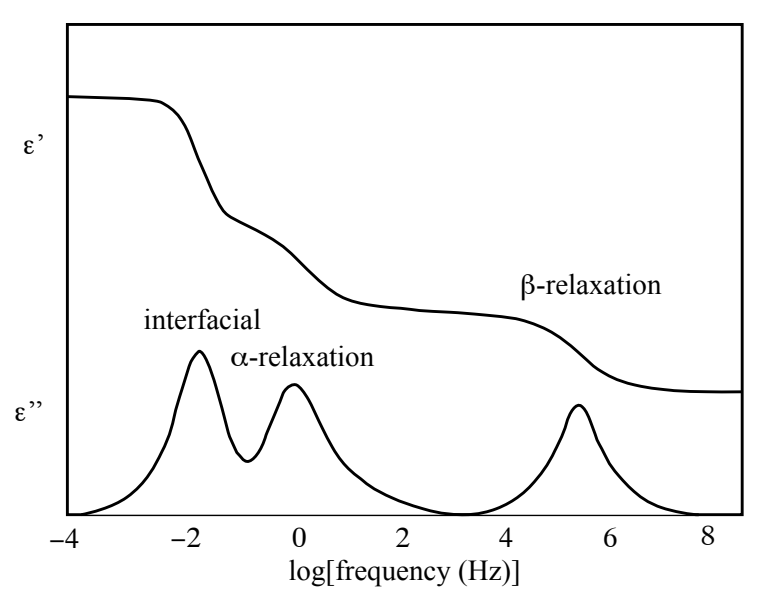

Figure 3. Schematic presentation of frequency dependence of $\boldsymbol{\varepsilon}^{\prime}$ and $\boldsymbol{\varepsilon}^{\prime \prime}$ for typical relaxation modes in polymers.

Further detail is given by Menczel \& Prime (2009).

EAB (the average of three measurements per condition), IM (the average of nine measurements per sample) and C and D (the average of ten measurements per sample) were measured. Details of the measurement procedures are provided in Arvia, Sheldon \& Bowler (2014) and Bowler, Sheldon, \& Arvia (2015). A subset of the data obtained is plotted in Figures 4, 5 and 6 for seven samples with red FREPR insulation. The mean value of each quantity is plotted and the error bar indicates one standard deviation in the measurements.

The decline in measured $\mathrm{EAB}$ and the increase in IM as a function of aging time, seen in Figure 4, indicates an increase in brittleness and stiffness of red FR-EPR as a function of aging time at $100{ }^{\circ} \mathrm{C}$ and $100 \mathrm{~Gy} / \mathrm{h}$. Similar effects are observed in black and white FR-EPR (Arvia, Sheldon \& Bowler, 2014). Increasing $C$ and $D$ as a function of aging time, Figures 5 and 6 respectively, indicates an increase in the real and imaginary parts of permittivity of the insulation brought about by aging mechanisms described in Section 3 of this paper. Considering the typical frequency-dependence of polymer permittivity presented in Figure 3, it is expected that $\mathrm{C}$ measured at $1 \mathrm{kHz}$ should be greater than that measured at $1 \mathrm{MHz}$, and this expectation is confirmed by the data presented in Figure 5. Further, the fact that $\mathrm{D}$ at $1 \mathrm{MHz}$ is larger than $\mathrm{D}$ at $1 \mathrm{kHz}$, Figure 6 , indicates that a dielectric relaxation peak exists closer to 1 $\mathrm{MHz}$ than to $1 \mathrm{kHz}$.

Correlation magnitudes were calculated by combining data from multiple measurements on 14 black, 14 white and 19 red FR-EPR insulated wire samples and are presented in Table 2. It can be seen that correlations between IM and EAB are relatively low, ranging between 0.75 and 0.79 . Correlations between $\mathrm{C}$ and $\mathrm{EAB}$ are a little poorer, ranging between 0.67 and 0.76 , whereas those between $\mathrm{D}$ and $\mathrm{EAB}$ occupy a wider range, between 0.66 and 0.88 .

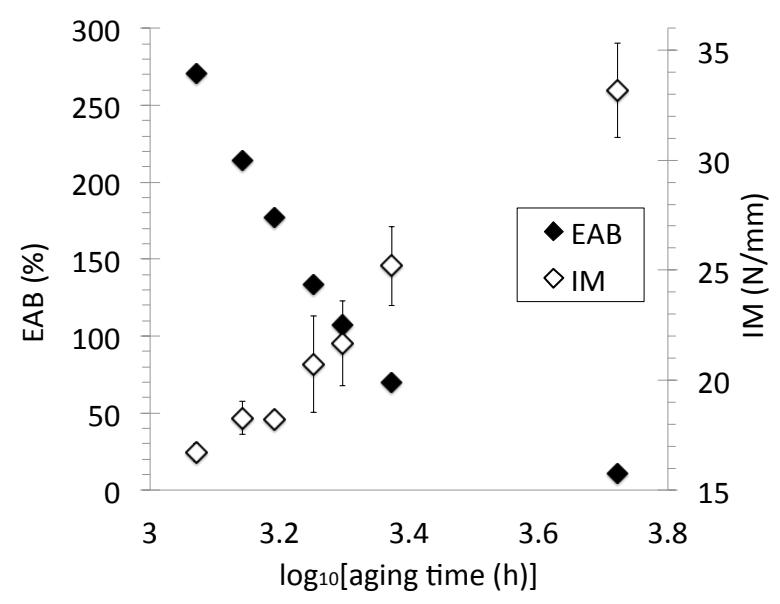

Figure 4. EAB and IM measured on seven red FR-EPR insulation samples aged at $100^{\circ} \mathrm{C}$ and $100 \mathrm{~Gy} / \mathrm{h}$ for times ranging from 1,177 to $5,230 \mathrm{~h}$.

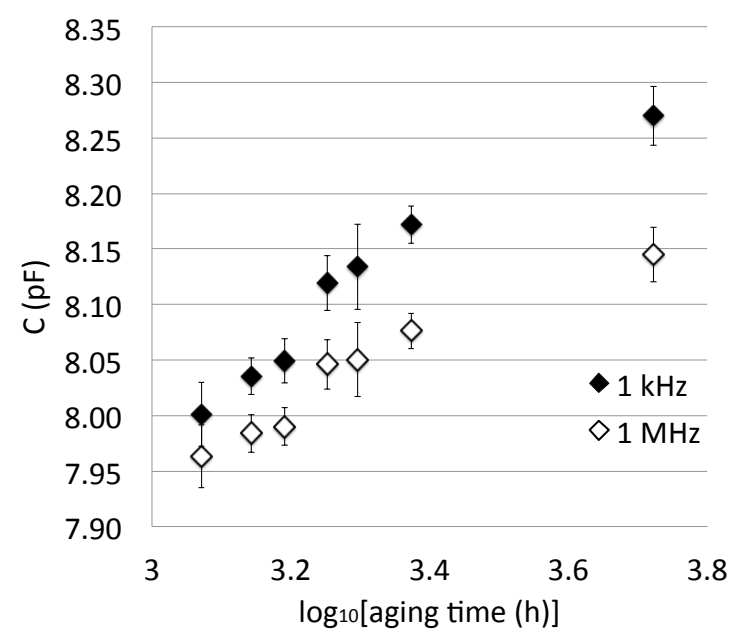

Figure 5. Capacitance measured at two frequencies for samples aged as described in the caption of Figure 4.

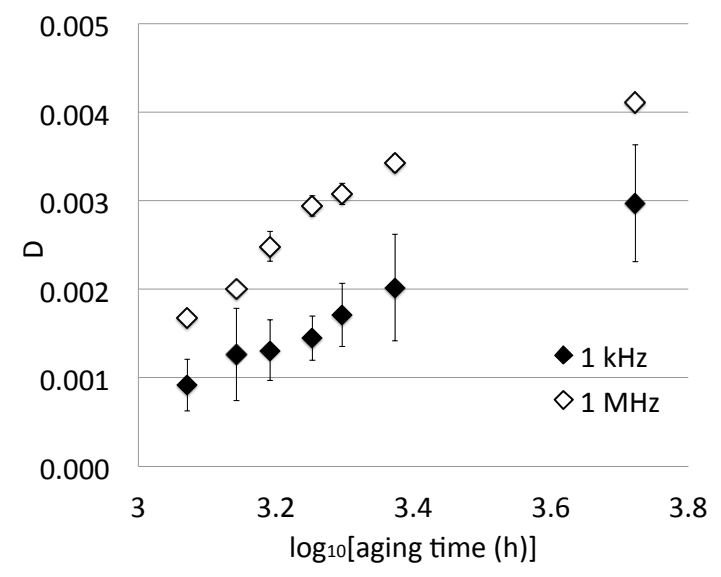

Figure 6. Dissipation factor measured at two frequencies for samples aged as described in the caption of Figure 4. 
Table 2.Correlation magnitudes between elongation-atbreak $(\mathrm{EAB})$ and the following quantities: indenter modulus (IM), capacitance (C) and dissipation factor (D) at two frequencies, measured on 47 flame-resistant EPR samples of three colors (black, white and red), aged at 80,90 or $100{ }^{\circ} \mathrm{C}$ and radiation level $100 \mathrm{~Gy} / \mathrm{h}$ for exposure times between

1,177 and 5,781 h (Arvia, Sheldon \& Bowler, 2014).

\begin{tabular}{l|c|c|c|c|c|c}
\hline & \multicolumn{2}{|c|}{ Black } & \multicolumn{2}{c|}{ White } & \multicolumn{2}{c}{ Red } \\
\cline { 2 - 7 } EAB & EAB & IM & EAB & IM & EAB & IM \\
\hline $\mathbf{C}, \mathbf{1} \mathbf{~ k H z}$ & 1 & 0.79 & 1 & 0.78 & 1 & 0.75 \\
\hline $\mathbf{C}, \mathbf{1} \mathbf{~ M H z}$ & 0.73 & 0.77 & 0.67 & $\mathbf{0 . 8 9}$ & 0.72 & $\mathbf{0 . 9 6}$ \\
\hline $\mathbf{D}, \mathbf{1} \mathbf{~ k H z}$ & 0.66 & $\mathbf{0 . 8 8}$ & 0.71 & $\mathbf{0 . 9 2}$ & 0.76 & $\mathbf{0 . 9 6}$ \\
\hline $\mathbf{D}, \mathbf{1} \mathbf{M H z}$ & 0.73 & $\mathbf{0 . 8 6}$ & 0.71 & $\mathbf{0 . 9 2}$ & $\mathbf{0 . 8 8}$ & $\mathbf{0 . 9 4}$ \\
\hline
\end{tabular}

The capacitance $\mathrm{C}$ and dissipation factor D correlate more strongly with IM than does EAB, for all colors of FR-EPR studied. In particular, correlation magnitudes between D and IM range between 0.86 and 0.96 , much higher than between EAB and IM. This may be due to crystallinity of the EPR samples since, as mentioned in Section 4.1, it has not been possible to obtain satisfactory correlations between $\mathrm{IM}$ and $\mathrm{EAB}$ in the case of semi-crystalline polymers (EPRI, 2005). Further research is needed on a wider range of sample material to determine which of these is the best indicator of aging.

Looking more closely at the correlation magnitudes given in Table 2 it can be seen that those values for C or D correlated with IM increase as color changes from black to white to red. Conversely, the correlation magnitude between measured values of EAB and IM increase as color changes in the reverse order: from red to white to black. This indicates that the colorant has opposite effects on the mechanical and dielectric loss properties of FR-EPR.

A detailed discussion of the colorants used in these insulation materials is beyond the scope of this work but, in general, polymer colorants are either dyes or pigments. Dyes suffer from the disadvantages of being prone to bleeding, being reactive with other ingredients in the polymer formula and with degradation products, of degrading on exposure to light and of poor heat stability. For these reasons, most polymers are colored using pigments - dry powders dispersed in the polymer. Chemical agents are employed during the processing of the polymer to effectively disperse and stabilize the pigment powder. Different colors are achieved using different pigments, which also may require use of different chemicals for dispersion and stabilization (Lutz \& Grossman, 2001). For these reasons it is not surprising that differently colored
FR-EPR responds differently to mechanical and dielectric tests, as indicated by the results presented in Table 2 . Further research is needed to elucidate the effects of colorant on polymer aging.

\section{CONCLUSION AND FUTURE WORK}

The deficiencies exhibited by present mechanical monitoring methods for cable insulation, such as the inability to obtain satisfactory correlations between IM and EAB for semi-crystalline polymers, Section 4, may be addressed by seeking new indicators of polymer degradation that can be measured nondestructively. To this point, it has been demonstrated in the work presented here that agingrelated changes in dielectric properties of the insulation material can be monitored using a capacitive sensor.

Practically speaking, measurements of cable capacitance and dissipation factor can be made on samples in situ by means of a clamp capacitor, such as that shown in Figure 2, adapted for the particular cable dimensions of interest. Another concept is the permanent placement of sensing patches, which may be periodically excited by application of a voltage across contact pads shown in Figure 7 . The possibility of in situ monitoring by permanently-placed electrodes is one potential advantage of the capacitive sensing approach over mechanical property measurements made using an indenter. The practical implementation of the sensor shown in Figure 7 will be examined in future work.

Samples of XLPE and EPR/EPDM will be aged according to an experimental plan that takes into account the important discoveries summarized in Section 3 - in particular that aging temperatures below the melting point and low dose rates should be employed. New indicators of aging, relevant to several electromagnetic NDE techniques; capacitive, terahertz and infrared, will be sought. Further, the aging mechanisms that underlie measurable changes will be elucidated taking into account variations in polymer formulation.

In conjunction with the identification of new indicators of polymer aging, proposal of a new acceptance criterion for cable insulation based on breakdown voltage $\left(\mathrm{V}_{\mathrm{BD}}\right)$, rather than $\mathrm{EAB}$, will be considered. In this context, $\mathrm{V}_{\mathrm{BD}}$ will also be measured on aged samples of XLPE and EPR/EPDM and correlated with EAB, IM, C and D.

\section{ACKNOWLEDGEMENTS}

The Japan Nuclear Energy Safety (JNES) Organization prepared the samples and provided elongation-at-break data. Analysis and Measurement Services (AMS) Corporation loaned the Indenter Polymer Aging Monitor used in this study. This work was funded in part by the United States Department of Energy under contract number DENE0008269. Robert Sheldon created Figure 2 and Danielle Kimler created Figure 7. 


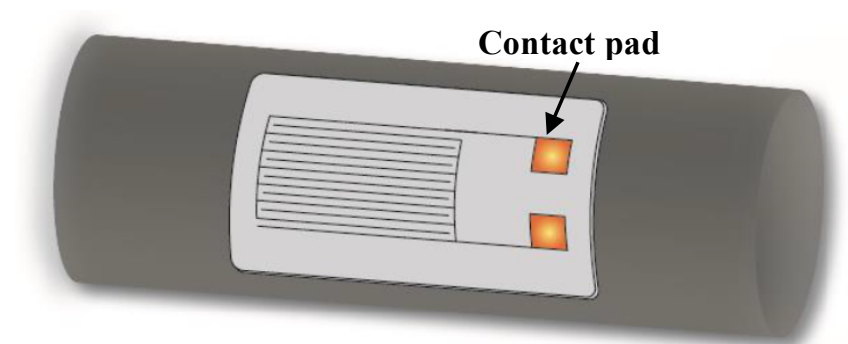

Figure 7. Concept schematic of an interdigital capacitor in permanent contact with cable jacket. Electrical contact pads for periodic excitation and data collection are shown.

\section{REFERENCES}

Analysis and Measurement Services Corporation. (2014). Indenter for cable condition monitoring. Online at: http://www.ams-corp.com/wpcontent/uploads/2012/07/Indenter.pdf .

Anastasi, R. F., \& Madaras, E. I. (2005). Application of ultrasonic guided waves for aging wire insulation assessment. Materials Evaluation, 63, 143-147.

Arvia, E., Sheldon, R. T. \& Bowler, N. (2014). A capacitive test method for cable insulation degradation assessment, Conference on electrical insulation and dielectric phenomena (514-517), October 19-22, Des Moines, IA.

ASTM International (2013). Standard Test Methods for Vulcanized Rubber and Thermoplastic ElastomersTension, Designation: D412-06a.

Bair, H. E. (1973). Exudation of an antioxidant additive from thin polyethylene films. Polym. Eng. Sci., 1973, 13, 435-439.

Billingham, N. C., Bott, D. C., \& Danke, A. S. (1981). Chapter 3. In Developmental Polymer Degradation, p. $63 \mathrm{ff}$.

Board, B. L., \& Ruddell, H. J. (1982). Investigation of Premature Depletion of Stabilizers from Solid Polyethylene Insulation. International Wire and Cable Symposium Proceedings (300-312).

Bowler, N., Sheldon, R. T. \& Arvia, E. M. (2015). A new test method for cable insulation degradation assessment: capacitive sensing, $9^{\text {th }}$ International conference on nuclear power plant instrumentation, control \& human-machine interface technologies (NPIC \& HMIT 2015), February 21-26, Charlotte, NC.

British Standard Guide (2001). High-Voltage Test Techniques-Partial Discharge Measurement, Designation: IEC60270.

Celina, M., \& George, G. A. (1993). A heterogeneous model for the thermal-oxidation of solid polypropylene from chemiluminescence analysis. Polym. Degrad. Stab, 40, 323-335.
Celina, M., \& George, G. A. (1995). Heterogeneous and homogeneous kinetic analyses of the thermal-oxidation of polypropylene. Polym. Degrad. Stab, 50, 89-99.

Celina, M., Gillen, K. T., \& Clough, R. L. (1998). Inverse temperature and annealing phenomena during degradation of crosslinked polyolefins. Polym. Degrad. Stab., 50, 231-244.

Chapiro, A. (1962). Radiation Chemistry of Polymeric Systems. New York: Interscience publishers.

Chen, T., \& Bowler, N. (2012a). A capacitive probe for quantitative nondestructive evaluation of wiring insulation. NDT\&E International, 52, 9-15.

Chen, T., \& Bowler, N. (2012b). Analysis of a capacitive sensor for the evaluation of circular cylinders with a conductive core. Meas. Sci. Technol., 23, 10.

Chen, T., Bowler, N., \& Bowler, J. R. (2012). Analysis of Arc-Electrode Capacitive Sensors for Characterization of Dielectric Cylindrical Rods. IEEE Trans. Instrumentation and Meas., 61, 233-240.

Chung, Y. C., Amarnath, N. N., \& Furse, C. M. (2009). Capacitance and inductance sensor circuits for detecting the lengths of open- and short-circuited wires. IEEE Trans. Instrum. Meas., 58, 2495-2502.

Clough, R. L., \& Gillen, K. T. (1981). Combined environment aging effects: radiation-thermal degradation of polyvinylchloride and polyethylene. $J$. Polym. Sci. Polym. Chem. Ed., 19, 2041.

Clough, R. L., \& Gillen, K. T. (1992). Oxygen diffusion effects in thermally aged elastomers. Polym. Degrad. Stab., 38, 47-56.

Clough, R. L., Gillen, K. T., Campan, J. L., Gaussens, G., Schonbacher, H., T., Wilski, H., \& Machi, S. (1984). Accelerated aging tests for predicting radiation degradation of organic materials. Nucl. Safety, 25, 238.

Clough, R. L., Gillen, K. T., \& Quintana, C. A. (1985). Heterogeneous oxidative degradation in irradiated polymers. J. Polym. Sci. Polym. Chem. Ed., 23, 359377.

Conley, R.T. (1970). Thermal Stability of Polymers. New York: Marcel Dekker.

Desai, C., Brown, K., Desmulliez, M., \& Sutherland, A. (2008). Selection of wavelet for de-noising PD waveforms for prognostics and diagnostics of aircraft wiring. Conference on electrical insulation and dielectric phenomena (17-20), October 26-29, Quebec, Canada.

Dole, P., \& Chauchard, J. (1995). Determination of oxidation profiles of elastomeric materials .2. Correlation of macro (swelling) with micro (pinpoint DMA). Polym. Degrad. Stab., 47, 449-457.

Electric Power Research Institute (EPRI) (1994). LowVoltage Environmentally-Qualified Cable License Renewal Industry Report; Revision 1. TR-103841.

Electric Power Research Institute (EPRI) (2005). Initial Acceptance Criteria Concepts and Data for Assessing 
Longevity of Low-Voltage Cable Insulations and Jackets, EPRI Technical Report 1008211, March.

Fothergill, J. C., Dodd, S. J., Dissado, L. A., Liu, T., \& Nilsson, U. H. (2011). The measurement of very low conductivity and dielectric loss in XLPE cables: a possible method to detect degradation due to thermal aging. IEEE Trans. Dielectr. Electr. Insulation, 18(5), 1544-1553.

Furse, C., Chung, Y. C., Dangol, R., Nielsen, M., Mabey, G., \& Woodward, R. (2003). Frequency domain reectometry for on board testing of aging aircraft wiring. IEEE Trans Electromagn Compat., 45, 306315.

Furse, C., Chung, Y. C., Lo, C., \& Pendayala, P. (2006). A critical comparison of reflectometry methods for location of wiring faults. Smart Struct. Syst., 2, 25-46.

Gillen, K., Assink. R., \& Bernstein, R. (2005). Cable Polymer Aging and Condition Monitoring Research at Sandia National Laboratories Under the Nuclear Energy Plant Optimization (NEPO) Program.

Gillen, K. T., \& Clough, R. L. (1985). A kinetic model for predicting oxidative degradation rates in combined radiation-thermal environments. J. Polym. Sci. Polym. Chem. Ed., 23, 2683.

Gillen, K. T., \& Clough, R. L. (1989). Time temperature dose-rate superposition - A methodology for extrapolating accelerated radiation aging data to lowdose rate conditions. Polym. Degrad. Stab., 24, 137168.

Gillen, K. T., Clough, R. L., \& Quintana, C. A. (1987). Modulus profiling of polymers. Polym. Degrad. Stab., 17, 31-47.

Gillen, K. T., Celina, M., Clough, R. L., \& Wise, J. (1997). Extrapolation of accelerated aging data - Arrhenius or erroneous? Trends in Polym. Sci., 5, 250-257.

Haruna, T. (2003). Aspects of stabilization with phosphorous antioxidants in polymers. Macromolecuar Mater. Engng., 232(1), 119-131.

Hegazy, E. S., Sasuga. T., Nishii, M., \& Seguchi, T. (1992). Irradiation effects on aromatic polymers: 1. Gas evolution by gamma irradiation. Polymer, 33, $2897-$ 2903. Irradiation effects on aromatic polymers: 2 . Gas evolution during electron-beam irradiation. Polymer, 33, 2904-2910.

Howard, J. B. (1973). DTA for control of stability in polyolefin wire and cable compounds. Polym. Eng. Sci., 13, 429-434.

Howard, J. B. \& Gilroy, H. M. (1975). Some observations on long-term behavior of stabilized polyethylene. Polym. Eng. Sci., 15, 268-271.

Hosobuchi, M., Komatsu, M., Xie, X., Cheng, Y., Furukawa, Y., Ohki, Y., Mizuno, M., \& Fukunaga, K. (2013). Measurements of Thz absorption peaks in photo-degraded polyethylene and their assignment by quantum chemical calculations, Conference on electrical insulation and dielectric phenomena (10461049) October 20-23, Shenzhen, China.

International Atomic Energy Agency (IAEA) (2000). Assessment and management of aging of major nuclear power plant components important to safety: incontainment instrumentation and control cables, vol. 1, December. IAEA-TECDOC-1188.

International Atomic Energy Agency (IAEA) (2012). Assessing and managing cable aging in nuclear power plants. IAEA Nuclear Energy Series, No. NP-T-3.6.

International Electrotechnical Commission (IEC) (1996). Determination of long-term radiation aging in polymers - part 2: procedure for predicting aging at low dose rates. IEC1244-2.

Japanese Standards Association (2000). Test methods for rubber and plastic insulated wires and cables, JIS C 3005:2000, Section 4.16.

Japan Nuclear Energy Safety (JNES) Organization (2009). Final Report of Assessment of Cable Aging for Nuclear Power Plants, July. JNES-SS-0903.

Joichi, K., \& Yoshitomo, U. (2003). Radiation resistivity of polymeric materials with data tables. JAERI-Data/Code 2003-015.

Jonscher, A. K. (1983). Dielectric relaxation in solids. London: Chelsea Dielectrics Press.

Kramer, E., \& Koppelmann. (1986). Measurement of oxidation stability of polyolefins by thermal-analysis. J., Polym. Degrad. Stab., 16, 261-275.

Kurihara, T., Takahashi, T., Honma, H., \& Okamto, T. (2011). Change of tensile strength due to non-uniform thermal deterioration of XLPE sheets. IEEJ, Trans. Fund. Matr., 131, 878-883.

Lutz, J. T. Jr., \& Grossman, R. F. (Eds.). (2001). Polymer modifiers and additives. New York: Marcel Dekker.

Menczel, J. D. \& Prime, R. B. (2009). Thermal analysis of polymers. Wiley.

Meyer, R. A., Bouquet, F. L., \& Alger, R. S. (1956). Radiation induced conductivity in polyethylene and Teflon. J. Appl. Phys., 27(9), 1012-1018.

Osawa, Z. (1992). Degradation and Stabilization of Polymers. Musashino Kurieito, Co., Ltd.

Perera, M. C. S., \& Hill, D. J. T. (1999). Radiation chemical yields: $G$ values, Polymer handbook, 4th edn. John Wiley \& Sons, Inc., II/481-497.

Pires, M., Mauler, R. S. \& Liberman, S. A. (2004). Structural characterization of reactor blends of polypropylene and ethylene-propylene rubber. J. Appl. Polymer Sci., 92(4), 2155-2162.

Placek, V. (2005). Assessment of parameters for simulation of thermal aging of materials in nuclear power plants using DSC. J. Thermal Analysis and Calorimetry, 80, 525-528.

Sandia National Laboratories Report (SAND) (1986). Status Report on Equipment Qualification Issues Research and Resolution. NUREG/CR-4301, SAND85-1309. 
Sandia National Laboratories Report (SAND) (2010). Review of Nuclear Power Plant Safety Cable Aging Studies with Recommendations for Improved Approaches and for Future Work. SAND 2010-7266.

Seguchi. T., Haruyama. Y., \& Sugimoto. M. (2013). Temperature dependence of gas evolution from polyolefins on irradiation under vacuum. Radiat. Phys. Chem., 85, 124-129.

Seguchi, T., Hashimoto, S., Arakawa, K., Hayakawa, N., Kawakami, W., \& Kuriyama, I. (1981). Radiationinduced oxidative degradation of polymers. I. Oxidation region in polymer films irradiated in oxygen under pressure. Radiat. Phys. Chem., 17, 195-201.

Seguchi, T., Tamura, K., Ohshima, T., Shimada, A. \& Kudoh, H. (2011). Degradation mechanisms of cable insulation materials during radiation-thermal aging in radiation environment. Radiat. Phys. Chem., 80, 268273.

Seguchi, T., Tamura, K., Shimada, A., Sugimoto, M., \& Kudoh, H. (2012). Mechanism of antioxidant interaction on polymer oxidation by thermal and radiation aging. Radiat. Phys. Chem., 81, 1747-1751.

Sekii, Y. (2007). Influence of antioxidants and cross-linking on the crystallinity of XLPE dielectrics. Conference on electrical insulation and dielectric phenomena (719722), October 14-17, Vancouver, Canada.

Sheldon, R. T., \& Bowler, N. (2014). An interdigital capacitive sensor for nondestructive evaluation of wire insulation. IEEE Sensors J., 14, 961-970.

Shimada, A., Sugimoto, M., Kudoh, H., Tamura, K., \& Seguchi, T. (2012). Radiation Aging Technique for Cable Life Evaluation of Nuclear Power Plant, IEEE Trans. Dielectr. Insul., 19, 1768-1773.

Simmons, K. L., Ramuhalli, P., Brenchley, D. L., Coble, J. B., Hashemian, H. M., Konnick, R. \& Ray, S. (2012). LWRS Program-NDE R\&D Roadmap for Determining Remaining Useful Life of Aging Cables in Nuclear Power Plants, PNNL-21731. September.

Smith, P., Furse, C., \& Gunther, J. (2005). Analysis of spread spectrum time domain reflectometry for wire fault location. IEEE Sensors J, 5, 1469-1478.

Sugimoto, M., Shimada, A., Kudoh, H., Tamura, K., \& Seguchi, T. (2013). Product analysis for polyethylene degradation by radiation and thermal aging. Radiat. Phys. Chem., 82, 69-73.

Tamblyn, J. W., \& Newland, G. C. (1965). Induction period in aging of polypropylene. J. Appl. Polym. Sci., 9, 2251-2260.

Ugbolue, S. C. O. (Ed.). (2009). Polyolefin fibers: Industrial and medical applications. Elsevier.

Verardi, L., Fabiani, D., \& Montanari, G. C. (2014). Electrical aging markers for EPR-based low voltage cable insulation wiring of nuclear power plants. Radiat. Phys. Chem., 94, 166-170.

White II, G., Bernstein, R., \& Gillen, K. T. (2012). Current and ongoing cable aging research to support life extension decisions, Trans. Am. Nuclear Soc., 107, 438440.

White, J., Tucholski, E. J., \& Green, R. E. (2003). Nondestructive testing of aircraft and spacecraft wiring. Materials Evaluation, 61, 1315-1320.

White, C. C., Wagenblast, J., \& Shaw, M. T. (2000). Separation, size reduction, and processing of XLPE from electrical transmission and distribution cable. Polymer Engng. Sci., 40(4), 863-879.

Wilski, H., Rosinger, S., \& Diedrich, G. (1980). LangzeitBestrahlung von Rohren aus Polybuten-1. Kunstoffe, $70,221$.

Wise, J., Gillen, K.T., \& Clough, R. L. (1995). An ultrasensitive technique for testing the Arrhenius extrapolation assumption for thermally aged elastomers. Polym. Degrad. Stab., 49, 403-418.

Wise, J., Gillen, K. T., \& Clough, R. L., (1997). Quantitative model for the time development of diffusion-limited oxidation profiles. Polymer, 38, 19291944.

Wright, K. J., \& Lesser, A. J. (2001). Crystallinity and mechanical behavior evolution in ethylene-propylene random copolymers. Macromolecules, 34, 3626-3633.

Wundrich, K. (1968). Die Bestandigkeit von Kunststoffen Gegen Energiereiche Strahlen und Ihre Prufung. Material Pruefung, 10 (7), 217.

\section{BIOGRAPHIES}

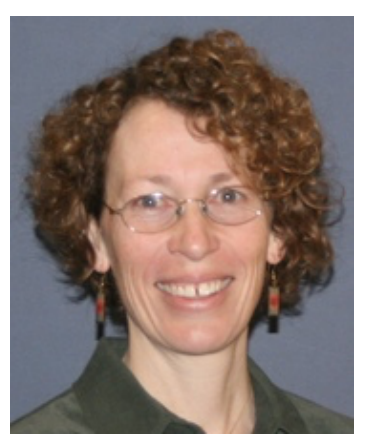

Nicola Bowler was born on 6 December 1968 in Hereford, England. She received a B.Sc. degree in physics from the University of Nottingham, UK, in 1990 and the Ph.D. degree from the University of Surrey, UK, in 1994, for theoretical work in the field of eddy-current nondestructive evaluation (NDE). She moved to the Center for NDE, Iowa State University, in 1999 and in 2006 was appointed Associate Professor of Materials Science and Engineering (MSE) at Iowa State University. She was promoted to the rank of full Professor in 2012. Her research interests include engineering the electromagnetic properties of composite materials by analysis and design, electromagnetic NDE of dielectrics and structural polymermatrix composites: Inventing new NDE techniques and improving accuracy in capacitive, inductive and microwave NDE, and broadband dielectric spectroscopy. She served as a Senior Associate Editor of the IEEE Transactions on Dielectrics and Electrical Insulation for two years, as Technical Editor of the Journal of Nondestructive Evaluation, published by Springer, for two years and is presently Associate Editor of Measurement Science and Technology, published by the Institute of Physics. Nicola 
was awarded the Akinc Excellence in Teaching Award in 2011, by the MSE Department, in recognition of outstanding teaching performance, and the Akinc Excellence in Research Award in 2012 in recognition of outstanding achievement in research. Nicola was elected Fellow of the Institute of Physics in 2013 and is an invited member of the Science Advisory Board in North America of Institute of Physics Publishing, since 2014.

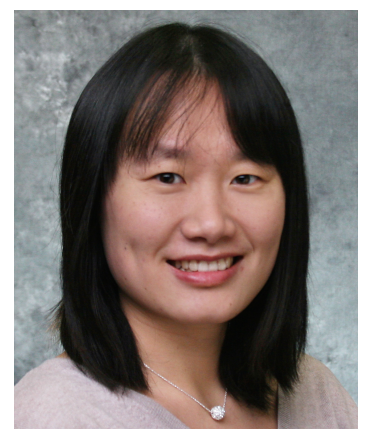

Shuaishuai Liu was born in Lianyungang, Jiangsu Province, China on 23 November 1992. She received her B.S. degree in Materials Science and Engineering from Jiangsu University, China, in 2013. She studied for one year as an exchange student in the department of Materials Science and Engineering in Yeungnam University, Daegu, South Korea and is currently enrolled in a $\mathrm{PhD}$ program in the department of Materials Science and Engineering at Iowa State University, USA. Shuaishuai has conducted research into the chemical synthesis of photocatalyst composites and into the mechanisms underlying permittivity change in poly(tetrafluoroethylene) under tensile strain. Her present research focus is into the degradation of nuclear power plant cable insulation materials due to irradiation and thermal aging. Shuaishuai was awarded Runner Up position for Oral Presenter under the theme of Environment in the $19^{\text {th }}$ Tri-U International Joint Seminar and Symposium "Role of Asia in Communities and Sustainable Development," which took place at Bogor Agricultural University, Indonesia in 2012. 